\title{
Annals of Clinical Microbiology and

\section{Genotypic detection of rifampicin and isoniazid resistant Mycobacterium tuberculosis strains by DNA sequencing: a randomized trial}

\author{
Amina Abdelaal ${ }^{\dagger 1}$, Hassan Abd El-Ghaffar ${ }^{\dagger 1}$, Mohammad Hosam \\ Eldeen Zaghloul* ${ }^{* 1}$, Noha El mashad ${ }^{\dagger 1}$, Ehab Badran ${ }^{\dagger 1}$ and Amal Fathy ${ }^{\dagger 2}$
}

\begin{abstract}
Address: ${ }^{1}$ Clinical pathology department, Faculty of medicine, Mansoura university, Mansoura, Egypt and ${ }^{2}$ Thoracic medicine department, Faculty of medicine, Mansoura university, Mansoura, Egypt

Email: Amina Abdelaal - Amina_abdelaal@yahoo.com; Hassan Abd El-Ghaffar - haabd_elghaffar@mans.edu.eg; Mohammad Hosam Eldeen Zaghloul* - hosam_z@yahoo.com; Noha El mashad - nmashad@hotmail.com; Ehab Badran - ehabrkha@yahoo.com; Amal Fathy - ml_fthy@yahoo.com

* Corresponding author †Equal contributors
\end{abstract}

Published: 16 February 2009

Annals of Clinical Microbiology and Antimicrobials 2009, 8:5 doi:10.1 I86/1476-07I I-8-5

This article is available from: http://www.ann-clinmicrob.com/content/8/I/5

(C) 2009 Abdelaal et al; licensee BioMed Central Ltd.

This is an Open Access article distributed under the terms of the Creative Commons Attribution License (http://creativecommons.org/licenses/by/2.0), which permits unrestricted use, distribution, and reproduction in any medium, provided the original work is properly cited.
Received: 13 February 2009

Accepted: 16 February 2009

\begin{abstract}
Correction to Genotypic detection of rifampicin and isoniazid resistant Mycobacterium tuberculosis strains by DNA sequencing: a randomized trial Amina Abdelaal, Hassan Abd ElGhaffar, Mohammad Hosam Eldeen Zaghloul, Noha El mashad, Ehab Badran, Amal Fathy Annals of Clinical Microbiology and Antimicrobials 2009, 8:4 (30 January 2009)
\end{abstract}

\section{Correction}

We lately discovered an accidental mistake, our manuscript [1] needs some important corrections; we offer our sincerest apologies and correct the text as under.

B.15.8 in sentence 2, asparagine is converted to aspartate.

B.15.11 in sentence 2, tyrosine is converted to threonine.

Table 9, asparagine is converted to aspartate, tyrosine is converted to threonine.

\section{References}

I. Genotypic detection of rifampicin and isoniazid resistant Mycobacterium tuberculosis strains by DNA sequencing: a randomized trial Amina Abdelaal, Hassan Abd EI-Ghaffar, Mohammad Hosam Eldeen Zaghloul, Noha El mashad, Ehab Badran, Amal Fathy. Annals of Clinical Microbiology and Antimicrobials 2009, 8:4. 